to give service to G.P.s one feels are doing a first-class job.

The third need you express very well. "General practitioners should be enabled to work in conditions which give them time and opportunity to do their job properly." Have you been re-reading the passage in the Draft Report of the Medical Planning Commission, 1942, describing the Model Health Centre ? That is what is now needed to provide general practitioners with the conditions for modern practice. Only in health centres can the G.P. find the opportunity for collaboration with his fellow practitioners, of organizing his work on modern lines, of sharing his unique experience with other health workers, and of taking part fully in preventive and educational measures. The G.P. must be retained and has a vital part to play in any health service. The hospital service can provide him with some of the tools of the job; the health centre can provide others; and in a united effort patients could be treated at home or in hospital whichever was best; and British general practice could continue to offer a new lead to others.-I am, etc.,

$$
\begin{aligned}
& \text { Pathological Laboratory, } \\
& \text { Kingston Hospital, }
\end{aligned}
$$

\section{Stark Murray}$$
\text { Kingston-upon-Thames, Surrey. }
$$

SIR,-The perennial attacks by eminent men on general practice, such as the one you refer to in your leading article (May 11, p. 1245), though intrinsically tedious, are an interesting phenomenon. Why is it that the most successful and popular part of the Health Service attracts the most criticism ? I refuse to believe these first-rate men are guilty of envy. Might I suggest, however, that the N.H.S. concept of the general practitioner is altogether too paternalistic for many of the middle classes? May not those who are, or consider themselves to be, in control of their own destiny resent being on the panel of one particular doctor? We understand that Americans, who pride themselves on their individualism, are wont to shop from doctor to doctor. Dr. Max Clyne and his colleagues found in Middlesex that many patients liked a change of doctor for no readily ascertainable reason. ${ }^{1}$

Even if we do not sympathize with this middle-class attitude, both Government and profession would do well to acknowledge it. As the cost of private medical attention is prohibitive to all but a few might not the State assist private patients financially ? It could undertake to pay, say, $75 \%$ of the cost of each prescription, and $50 \%$ of that of each item of service by the private general practitioner (but, perhaps, not pay more than $£ 1$ towards any one item). Needless to say the State should not be expected to pay twice (any more than the individual). Private patients who availed themselves of this assistance, therefore, would be obliged to withdraw from the list of any National-Health practitioner they happened to be on, thereby saving capitation fees. I do not suggest any prescribed scale of fees for particular items (as in Norway). Inevitably it would lead to much paper work and wrangling. Patients whose circumstances altered for the worse, or who developed costly illnesses, could always return to a panel, and thereby be protected against the possible hardship of making direct payments. Living and practice expenses in this country are so variable anyway that a scale that was adequate in one area might well be inadequate in another.

Also, the encouragement of private practice by such means could enable general practitioners to run efficient practices in areas where costs are too high to do this on National Health capitation fees alone. If doctors treating these State-subsidized private patients were obliged to accept others as National Health patients, the latter would, incidentally, benefit. The patients' contributions towards the cost of drugs and fewer capitation fees might well make for an overall saving of public money, a secondary but nevertheless important consideration.

An "intimate and personal" relationship between general practitioner and patient may well be desirable, and is certainly time honoured. It is, however, a voluntary one between the two parties concerned upon which the doctor has no business to insist. All he should expect is every help in his none too easy task.-I am, etc.,

Barton-on-Humber, Lincs.

S. H. F. HOWARD.

REFERENCE

Clyne, M. B., Hawes, A. J., Lask, A., and Saville, P. R., J. Coll. gen. Practit., $1963, \ddot{6}, 87$.

\section{Treatment of Umbilical Hernia}

Sir,--Your annotation (May 11, p. 1249), teaching that umbilical hernia in infants should not be treated, begins with the statement that strangulation is rare, which is poor consolation to the mother of a baby who develops it. It ends by quoting an American paper ${ }^{1}$ which "showed conclusively that strapping delayed spontaneous healing."

This short and vague paper is founded exclusively on premature infants, the great majority being negroes, a race well known to be particularly liable to this condition. Even so, it is surprising to learn that in such a group two papers quoted describe over $80 \%$ as having either umbilical or inguinal hernias-no wonder the author describes them as a fertile field for his investigations.

The hernias were " evaluated and grouped according to whether the hole and protrusion measured less or more than one centimetre in circumference." Later in the paper the author talks of the grouping of cases less than one centimetre in diameter, which makes more sense but does not lead to confidence in his accuracy. Of the 111 larger hernias left untaped, 31 remained " unresolved," presumably at 10 years of age. Of the 39 that were taped, 16 were finally healed. The taping used was elastic, a common fault of technique, and its aim .was defined as being "to constrict the skin over the hernial site." No mention is made of whether the bowel was stopped protruding, and no suggestion as to why protrusion should hurry up the healing of a gap which it presumably stretches.

"Supra-umbilical" hernia is mentioned but not defined, though if what I call a " semi-umbilical " hernia is meant its progress and treatment are quite different from those which come through the track of the shrunken umbilical cord.

Two large hernias were operated upon because they were "suspected at times of being associated with the infant's extreme irritability." Anyone who has seen the relief of mother and child when the vicious circle of discomfort-bawling-more protrusion-more discomfort-more bawling is broken by proper strapping will agree that the author's suspicion is probably correct.

I suggest, Sir, that this sort of thing just isn't good enough.-I am, etc.,

London W.1.

Denis Browne. REFERENCE

${ }^{1}$ Halpern, L. J., J. Amer. med. Ass., 1962, 182, 851. 